\title{
Call for Papers: \\ Special Issue on Structural Virology
}

\section{Deadline for Manuscript Submission: January 15, 2020}

\author{
Guest Editor: Reza Khayat, PhD; City University of New York
}

\begin{abstract}
Virology and Structural Biology are separate entities in scientific research. However, recent advances in structural biology techniques, particularly X-ray crystallography and electron microscopy, have brought forth a 'Resolution Revolution' changing the face of viral research in convergence with advances in molecular biology techniques. The emergence of 'Structural Virology' has provided valuable insight in to the workings of viruses encompassing their life cycle, infection strategy, and structure-function relationships. This evolution has precipitated the discovery of novel drug targets and therapeutic strategies to combat viral infections.
\end{abstract}

To highlight the many advances in this topic; the Journal Viral Immunology has conceptualized a Special Issue on Structural Virology. The chosen articles will underscore new directions and discoveries in structural virology and will harness the following areas:

- Viral life cycle

- Host interactions/infection

- Cellular and immune responses to viruses

- Viral membrane biology

- Bacteriophage biology

- Viral disease mechanisms

- Antiviral drug/drug targets

- New therapeutic strategies

We invite authors to submit papers in using techniques ranging from x-ray crystallography, electron microscopy, imaging, biophysics, membrane biology, molecular biology, pharmacology, and biochemistry that can unify the structural, functional, infection, and cell biology aspects of viruses.

The new deadline for manuscript submission is January 15, 2020. Please submit your articles online to our webbased manuscript submission and peer-review system at https://mc.manuscriptcentral.com/viral

Visit the Viral Immunology website to read more about the journal.

\section{Editorial questions?}

Contact the Managing Editor Karen Cloud-Hansen at kcloudhansen@liebertpub.com

Submit your paper for peer review online:

https://mc.manuscriptcentral.com/viral 